\title{
Capitalismo contemporâneo, desigualdades sociais e a crise de 2008
}

Leonardo de Araújo e Mota

Programa de Pós-Graduação em Desenvolvimento Regional da Universidade Estadual da Paraíba (UEPB)

Recebido: 02/10/2012 Versão revisada (entregue): 22/03/2013 Aprovado: 10/04/2013

\begin{abstract}
Resumo
O capitalismo é um sistema econômico inerentemente contraditório e instável, com variações que se processam no tempo e no espaço. Após a derrocada do socialismo real, o capital assumiu uma missão civilizatória cada vez mais ampla, distribuindo suas benesses e contradições em nível global. Neste artigo se pretende expor as mudanças no capitalismo contemporâneo a partir do fordismo até a crise de 2008, relacionando-as com as desigualdades econômicas e sociais. A recente crise - que teve origem no setor imobiliário (subprime) dos Estados Unidos e contagiou o mercado financeiro mundial, lançando o mundo em mais uma onda de recessão - parece apontar para um cenário pessimista no futuro. No entanto, alguns mecanismos presentes nas democracias modernas propiciaram, a um variado conjunto de movimentos, a contestação da atual ordem econômica e social em escala global - sugerindo a possibilidade de cenários alternativos.
\end{abstract}

Palavras-chave | Capitalismo; crise; democracia; desigualdades sociais.

Código JEL | G01; G28; P17.

\section{CONTEMPORARY CAPITALISM, SOCIAL INEQUALITY AND THE CRISIS OF 2008}

\begin{abstract}
Capitalism is an economic system inherently contradictory and unstable, with variations that take place in time and space. After the collapse of socialism, the capital assumed an even wider civilizing mission, spreading its gains and contradictions globally. This article aims to explain the changes in contemporary capitalism from Fordism to the crisis of 2008, relating them to the social and economic inequalities. The recent crisis - which originated in the real estate industry (subprime) in the United States and spread to the world financial markets, plunging the world into another wave of recession - seems to point to a pessimistic scenario in the future. However, some mechanisms present in modern democracies led to a varied set of motions, challenging the current economic and social order on a global scale - suggesting the possibility of alternative scenarios.
\end{abstract}

Keywords | Capitalism; crisis; democracy; social inequalities.

JEL-Code | G01; G28; P17. 


\section{CAPITALISMO CONTEMPORÁNEO, DESIGUALDADES SOCIALES Y LA CRISIS DE 2008}

\section{Resumen}

El capitalismo es un sistema económico intrínsecamente contradictorio e inestable, con variaciones que se procesan en el tiempo y en el espacio. Después de la caída del socialismo real, el capital asumió una misión civilizacional cada vez más amplia, extendiendo sus beneficios y sus contradicciones a nivel mundial. Este artículo pretende explicar los cambios en el capitalismo contemporáneo desde el fordismo hasta la crisis de 2008, relacionándolos con las desigualdades sociales y económicas. La reciente crisis - que se originó en el sector inmobiliario (subprime) en los Estados Unidos y se extendió a los mercados financieros mundiales, sumergiendo al mundo en una nueva ola de recesión - parece apuntar a un escenario pesimista en el futuro. Sin embargo, algunos de los mecanismos presentes en las democracias modernas condujeron a un conjunto variado de movimientos y al desafío del actual orden económico y social a escala mundial - lo que sugiere la posibilidad de escenarios alternativos.

Palabras-clave | capitalismo; crisis; democracia; desigualdades sociales.

Código JEL | G01; G28; P17.

\section{Introdução}

Embora o capitalismo seja inerentemente contraditório e instável, é necessário admitir também que existem vários "tipos de capitalismo", cuja dinâmica própria irá depender da presença deste sistema econômico no tempo e espaço.

O capitalismo do século XIX, capitaneado pela Revolução Industrial na Inglaterra e baseado no liberalismo econômico clássico, era caracterizado por sua profunda lógica de exploração e precários ou inexistentes sistemas de proteção social.

$\mathrm{Na}$ era do Estado do Bem-Estar social, o capitalismo vai adquirir uma face mais humana, na medida em que o Estado irá distribuir parte de suas benesses aos trabalhadores através de políticas de welfare. A partir da crise do petróleo de 1973, as políticas keynesianas de intervenção estatal na economia irão sofrer um revés, fazendo com que, nos anos 1980, os princípios do liberalismo, agora sob a insígnia do Estado mínimo ou neoliberalismo, ditem os novos rumos das políticas econômicas e sociais de muitos países, sobretudo após a Queda do Muro de Berlim, em 1989.

Em 2008, a crise do setor imobiliário (subprime) nos Estados Unidos contagia o mercado financeiro mundial, lançando o mundo em mais uma onda recessiva.

Neste sentido, este artigo pretende expor, resumidamente, as mudanças no capitalismo contemporâneo a partir do fordismo até a atual crise de 2008, relacionando tais episódios com o incremento das desigualdades econômicas. 


\section{O fordismo e a era de ouro do capitalismo}

O fordismo, cuja data inicial simbólica remete ao ano de 1914, quando Henry Ford estabeleceu a jornada de oito horas de trabalho e salários de 5 dólares ao dia, representou um sistema que conciliava uma produtividade crescente com o barateamento de bens de salário, tornando-se dominante após a II Guerra Mundial. Dessa forma, o padrão de vida da classe operária industrial melhorou significativamente nos países desenvolvidos, apesar da exploração da força de trabalho. Com o aumento do consumo social consolidado por intermédio de mecanismos institucionais, como a ampla sindicalização e a negociação coletiva legalizada, houve um equilíbrio entre o setor de bens de produção e o setor de bens de consumo durante um período que ficou conhecido como a Era de Ouro do capitalismo (1945-1973).

Esse modo de regulação do capitalismo, gerado após os traumas da recessão de 1929, buscava a generalização da industrialização, o pleno emprego e a diminuição das desigualdades, com o objetivo final de alcançar um desenvolvimento harmônico, progressivo e ilimitado (FRIGOTTO, 2011). Nos anos compreendidos entre 1950 e 1973, a economia mundial vivenciou um espetacular desenvolvimento, com o PIB mundial crescendo a uma média anual de 4,9\%, representando uma fase que não ocorria desde 1820 (GENTILI, 2011).

Nos Estados Unidos, esse modelo propiciou vários benefícios aos blue color, ou seja, operários sindicalizados de macacão azul que passaram usufruir de um nível de vida de fazer inveja à classe média brasileira, com suas casas de subúrbio com cercas baixas, carros de grande potência, vários eletrodomésticos, aposentadorias seguras e bons serviços públicos. As mulheres e os afrodescendentes, via de regra, estavam fora deste "paraíso", que, na realidade, veio a beneficiar totalmente apenas uns 20 países no mundo. Ser muito rico nesta época não era algo proveitoso, pois os impostos eram altíssimos.

Um ingrediente desagradável deste sistema era a rotina e o embrutecimento mental gerado pelas funções repetitivas desempenhadas nas fábricas. Em grande medida, é importante também lembrar que as políticas de welfare nos países capitalistas tinham como objetivo barganhar com os trabalhadores visando à contenção da ameaça soviética e seu modelo revolucionário de "solucionar" as demandas das classes trabalhadoras.

No Brasil, esse modelo de intervenção estatal dentro do capitalismo teve suas similaridades com aquilo que se denominou de Era Vargas. As circunstâncias de nossa industrialização, em virtude da condição periférica da economia brasileira, não ofereciam aos trabalhadores brasileiros as mesmas vantagens de seus colegas americanos e europeus. No entanto, para a classe média letrada, os bons empregos eram o funcionário público estável e bem remunerado, como também o afluente funcionário de uma multinacional, desfrutando de vários benefícios. 
Tais empregos estavam disponíveis para quem tinha uma boa educação e as jornadas de trabalho não costumavam ser estafantes. Para o restante da população, reinava a iniquidade social, com baixas taxas de escolaridade e salário mínimo com reduzido poder de compra. Mesmo assim, em meados dos anos sessenta os índices de desemprego eram baixíssimos quando comparados ao cenário atual: 1,5\% na Europa Ocidental, 1,3\% no Japão e 3,4\% na América Latina (GENTILI, 2011).

\title{
A decadência do fordismo e o neoliberalismo
}

Em meados da década de 1960, o ciclo de crescimento do fordismo (que também pode ser compreendido por Estado do Bem Estar) começa a declinar. A queda da produtividade e lucratividade corporativas nos Estados Unidos depois de 1966 marcou o início de um problema fiscal naquele país, com consequências sobre suas políticas sociais. As fábricas instaladas em países do Terceiro Mundo conseguiam os maiores lucros em virtude da precariedade das condições de trabalho e dos baixos salários. Mas a decisão dos países da OPEP de aumentar o preço do petróleo, elevando o preço do barril de US\$2,90 para US\$11,65 em apenas três meses, em 1973 teve efeito catastrófico sobre a economia mundial. A partir de então, foi quebrada a "rigidez" do fordismo, fato que levou as empresas a adotar novas estratégias de sobrevivência. Nas palavras de David Harvey (2000, p. 139-140):

\begin{abstract}
A mudança tecnológica, a automação, a busca de novas linhas de produto e nichos de mercado, a dispersão geográfica para zonas de controle do trabalho mais fácil, as fusões e as medidas para acelerar o tempo de giro do capital passaram ao primeiro plano das estratégias corporativas de sobrevivência em condições gerais de deflação. A profunda recessão de 1973, exacerbada pelo choque do petróleo retirou o mundo capitalista do sufocante torpor da "estagflação" (estagnação da produção de bens e alta inflação de preços) e pôs em movimento um conjunto de processos que solaparam o compromisso fordista.
\end{abstract}

O processo denominado de acumulação flexível, toytismo ou reestruturação produtiva, que coaduna elementos tecnológicos (automação, microeletrônica), econômicos (no período 1973-1992 o crescimento do PIB mundial foi de 3,0\%, em 1950-1973 havia sido de 4,9\% - e choque do petróleo) e sociais (perda do poder dos sindicatos ante a crise e desemprego) finda por desembocar naquilo que denominamos de globalização neoliberal.

Para sobreviver, o fordismo necessitava de uma economia pungente, que não existia mais. Na América Latina, no início da década de 1980, o desemprego 
urbano chegava a $6,7 \%$, passando a $10,1 \%$ em 1985, enquanto a taxa média de inflação atingiu, em 1989, a casa de 1.205\% (GENTILLI, 2011). Foi justamente neste período em que o Brasil ganhou "título" de campeão mundial em desigualdade social, fase somente superada anos após o plano real e a consequente estabilização da moeda.

A partir desse quadro econômico, a explicação hegemônica atribuiu a culpa do aumento das desigualdades à inflação. Para os neoliberais, os mercados da época fordista eram extremamente rígidos, os custos trabalhistas altos, os sindicatos poderosos e corporativos, o Estado irresponsável e as instituições do bem-estar generosas demais. Em poucas palavras, o problema não era a lógica acumulativa e contraditória do capital, mas um Estado grande, ineficaz e paternalista.

A partir daí, termos como desregulamentação, flexibilização, qualidade total, reengenharia, downsing, políticas de ajuste estrutural, fusões, mercados de capitais, fundos de pensões, Wall Street, terceirizações, desestatização, privatização, corporações transacionais, produtividade, competitividade e tantas outras povoaram o linguajar dos experts em administração e finanças, ao passo que também se multiplicaram as análises sociológicas sobre a globalização e suas desigualdades (IANNI, 2000; HELD; McGREW, 2001).

O desemprego estrutural tornou-se um fato inconteste e indissociável da lógica da globalização neoliberal, condicionado, tanto pela crise, como pelas mudanças tecnológicas. A título de exemplificação, entre 1998 e 2002, a Sprint Corporation aumentou a produtividade em 15\%, elevando sua renda em 4,3\%, ao mesmo tempo em que demitia 11.500 trabalhadores. Entre 1982 e 2002, a produção de aço nos Estados Unidos aumentou de 75 milhões de toneladas para 102 milhões de toneladas, na mesma medida em que o número de operários metalúrgicos caía de 289.000 para 74.000, tudo isso graças à revolução na informática, na microeletrônica e na automação industrial (SENNET'T, 2006).

Nos Estados Unidos, país com a economia mais pungente do hemisfério norte, as desigualdades sociais multiplicaram-se. A diferença entre os salários totais pagos aos executivos de grandes corporações e salários pagos ao trabalhador comum saltou de um coeficiente de 44,8 em 1973 para 172,5 em 1995. Homens com educação de nível superior, contando com um a cinco anos de experiência no mercado viram seus salários por hora cair em média 10,7\%, no período 19791995. Entre 1973 e 1993, o número de crianças brancas vivendo na pobreza nos Estados Unidos aumentou 52,6\%, de crianças hispânicas, $116 \%$ e de crianças negras, 26,9\%. Vale aqui lembrar que, uma vez que a pobreza conduz a um quadro de miséria e exclusão social, o estigma se instaura, e a destruição da personalidade e das redes sociais só faz agravar ainda mais o sofrimento (CASTELLS, 1999).

O Relatório das Nações Unidas de 1999 também revelou à humanidade, no crepúsculo do século XX, a exacerbação das desigualdades sociais na globalização. Somente os ativos dos três maiores multimilionários do mundo eram superiores 
ao Produto Nacional Bruto (PNB) conjunto de todos os países menos desenvolvidos e dos seus 600 milhões de habitantes. Ao mesmo tempo, aumentou o acesso ao desenvolvimento, tecnologia, industrialização e consumo a milhões de chineses, coreanos, indianos, malaios, tailandeses, chilenos, brasileiros e outros grupos de menor porte em vários países (PNUD, 1998).

Mais recentemente, observou-se também um deslocamento de poder do Ocidente para o Oriente e para alguns países do Sul. Embora embrionário, o aumento da riqueza nos países emergentes (BRICs) pode significar um turning point na economia mundial, pois cerca de metade do crescimento anual do PIB mundial advém hoje dessas economias emergentes (CARDOSO, 2010).

Entretanto, mesmo com alguns ganhos para determinadas classes que não tinham acesso ao consumo, como no caso da ascensão da "Classe C" no Brasil à bens e serviços antes disponíveis somente à classe média tradicional, não seria prudente afirmar que as desigualdades globais estejam diminuindo. Segundo dados de 2010, $0,5 \%$ da elite global possui $35,6 \%$ de toda a riqueza do planeta (CREDIT SUISSE, 2011).

\section{A crise de 2008: financeirização e desigualdades sociais}

A crise econômica de 2008, que impulsionou a atual recessão global, é um desdobramento da crise financeira internacional, precipitada pela falência do tradicional banco de investimento estadunidense Lehman Brothers, fundado em 1850. Em efeito dominó, outras grandes instituições financeiras quebraram, através de um processo também conhecido como "crise dos subprimes", que teve como epicentro o mercado imobiliário norteamericano.

Esta crise foi mais uma "bolha" criada pelo mercado financeiro, que desta vez utilizou títulos de hipoteca de casas vendidas a pessoas que geralmente não tinham condições de pagar por esses bens, para dinamizar a especulação financeira em torno desses títulos, que passavam a múltiplas mãos. Em poucas palavras, embora as hipotecas subprimes fossem vendidas à opinião pública dos Estados Unidos como um meio de solucionar o problema dos sem-teto, tratava-se de "transformar em devedores indivíduos desprovidos dos requisitos necessários à concessão de um empréstimo". (BAUMAN, 2010, p. 9). Ou seja, o objetivo era conseguir atrair os clientes Ninja (No Income, no Jobs, no Savings) para a realização do "sonho da casa própria".

Neste sentido, a lógica da atual crise está pautada em um processo que Bresser Pereira irá denominar de financeirização, que se constitui em "um arranjo financeiro distorcido, baseado na criação de riqueza artificial, ou seja, de riqueza financeira desligada da riqueza real ou da produção de bens e serviços." (BRESSERPEREIRA, 2010, p. 52). Em grande medida, o maior fluxo de capitais da 
economia mundial está vinculado a este setor, representando uma verdadeira ruptura entre a economia financeira e a real, entre os recursos destinados à produção e geração de empregos e àqueles meramente especulativos que cria capital através de transações bancárias envolvendo empréstimos e cobranças de juros.

Zygmunt Bauman (2010) denominará este processo de expansão contínua do crédito de capitalismo parasitário, no qual o mais importante é manter os indivíduos em um permanente estado de endividamento. Em grande medida, o capital busca sempre novas "terras virgens" para renovar-se e transformar as dívidas contraídas em permanentes fontes de lucro, seja através de cartões de crédito ou do crédito fácil, como no caso das hipotecas subprimes.

Mas quando a capacidade das pessoas de pagar suas dívidas se esgota, fato hoje bastante comum em virtude da estagnação dos salários e do desemprego, a crise irrompe. As consequências sociais desses episódios são dramáticas; algo muito além da simples mensuração dos índices das bolsas de valores. Quando os bancos vão à falência, as empresas não têm como financiar a produção, sendo obrigadas a demitir em massa, o que acaba gerando um ciclo perverso de desemprego e pobreza. Segundo dados da Organização Mundial do Trabalho, a crise financeira de 2008 elevou o número de desempregados de cerca de 20 milhões para 50 milhões ao final de 2009. Segundo a FAO, o número de pessoas subnutridas no mundo, por sua vez, aumentou em 11\% em 2009, superando, pela primeira vez, a casa de 1 bilhão de indivíduos famintos (BRESSER-PEREIRA, 2010).

O processo de financeirização da economia mundial teve seu início nos anos 1980, como parte da crença neoliberal nos mercados auto-regulados e eficientes que, supostamente, deviriam resolver os problemas oriundos da crise do Estado do bem-estar social, desmantelando-o. Os pressupostos keynianos/fordistas de regulação da economia pelo Estado, que surgiram como consequência da crise de 1929, foram contestados e acusados de retrógados ou ineficazes.

Nos sistemas desregulados, os profissionais de finanças trabalham com um tipo de ativo fictício que demanda convenções e confiança, ao passo que os demais empreendedores se envolvem em transações com produtos, mercadorias e serviços reais. Assim, os primeiros lidam com dígitos e gráficos complexos na tela de um computador (capital virtual), enquanto os segundos lidam com as pessoas e suas famílias, os produtos que produzem e seus empregos.

Mas na medida em que a economia virtual suplanta a economia real, a segunda pode ser desmontada rapidamente. Qualquer “inovação” ousada dos homens de finanças fazem sumir milhares de empregos e também abalam muitas instituições políticas. Um dos produtos mais conhecidos dessa economia fictícia são os derivativos, que praticamente não existiam até a década de 1990. Esses produtos financeiros alcançaram o valor de 20 trilhões de dólares em 2001 e de 38 trilhões em 2006. Por fim, o conjunto de variados serviços financeiros cresceu de 220 
trilhões em 2001 para alcançar a cifra de 380 trilhões em 2006, o que equivale a mais de cinco vezes o PIB mundial (CARDOSO, 2010). Assim, o grosso da economia mundial torna-se mais virtual que real.

A parte trágica desse cassino global está no recrudescimento das desigualdades sociais e na intensificação das crises cíclicas do capitalismo, trazendo uma série de infortúnios a milhares de indivíduos e suas famílias, enquanto são pagas enormes bonificações aos operadores financeiros por sua habilidade de incrementar as rendas capitalistas.

A financeirização da economia também está relacionada ao desenvolvimento tecnológico, com seus potentes computadores e softwares inteligentes, dispostos a circular rapidamente grandes somas de capital e calcular eventuais riscos. No entanto, apesar de toda a tecnologia implicada nesse processo, as crises aumentaram significativamente nas últimas décadas. Enquanto entre os anos de 1945 e 1971, o mundo passou por 38 crises financeiras, entre 1973 e 1997, houve 139 crises. Verificou-se apenas uma crise bancária de 1947 a 1975, mas irromperam 31 delas entre 1976 a 2008 (BRESSER-PEREIRA, 2010).

\section{Política e sociedade em tempos de crise sistêmica}

As análises socioeconômicas são instrumentos importantes para qualquer análise social, mas raramente são suficientes para diagnosticar a angústia que é produzida por um cenário de intensa injustiça provocada pelas desigualdades sociais, pelo desemprego e todas as formas de opressão física e psicológica que acompanham esses processos sociais. Pobreza, desigualdades e desemprego tem sido o foco de muitas análises sociológicas, como também a preocupação de muitos psicanalistas. Trata-se, portanto, tanto de um fenômeno sociológico, quanto psicológico e existencial (MOTA, 2004).

Em Contrafogos, Pierre Bourdieu (1998) irá fazer uma análise crítica da hegemonia neoliberal, sobretudo naquilo que ele conceituou como a mão esquerda e a mão direita do Estado. A mão esquerda seria composta pelos "trabalhadores sociais", como assistentes sociais, médicos, educadores etc. No que se refere à mão direita do Estado, estão incluídos nesta categoria os burocratas do ministério das Finanças, dos bancos públicos e privados e dos gabinetes ministeriais. Os trabalhadores sociais pertencem aos ministérios "gastadores", enquanto os tecnocratas ligados às finanças representariam o setor dinâmico e avançado do Estado. A palavra flexibilização, por exemplo, que pretende denotar ser flexível com relação ao trabalho, na verdade representa apenas redução de conquistas trabalhistas. A dominação neoliberal não é apenas econômica, mas também simbólica.

Com relação à recente crise de 2008, Alain Touraine (2011) irá chamar atenção para o grande custo social da crise, que finda por atingir duramente os 
trabalhadores que, como classe, se fragmentam cada vez mais. Este autor irá denunciar o silêncio e a apatia de assalariados, sindicatos, militantes e intelectuais perante a crise como o sinal de um permanente estado de desespero diante do inevitável e suas consequências desastrosas para todo o tecido social. Os trabalhadores não se representam mais enquanto categoria social. Nas suas palavras:

[...] a sede de consumo impulsionou os pobres a desdenhar dos extremamente pobres, sobretudo para diferenciar-se deles [...] a crise econômica, o aumento do desemprego, a não adaptação do ensino geral e profissional mostram a vida social como um terreno bombardeado pela pobreza e pela impotência, que se instala no coração de muitos sistemas políticos, tanto de esquerda quanto de direita. A sociedade não existe mais [...] as relações entre grupos não permitem mais perceber estes grandes conjuntos que até então denominávamos classes sociais, e que correspondiam a modos de vida e relações sociais específicas (TOURAINE, 2011, p. 68-69).

Partindo de um sociólogo como Alain Touraine, conhecido outrora como grande entusiasta dos Movimentos Sociais, uma frase como "a sociedade não existe mais" representa um alerta. $\mathrm{Na}$ realidade, o que o autor pretende destacar é o enorme fosso que existe atualmente entre os agentes que controlam o sistema financeiro global e as instituições que deveriam proteger os indivíduos dos efeitos das crises econômicas. Em uma sociedade onde os laços sociais e profissionais tornaram-se extremamente fragmentados, persiste a sensação de que a política institucional pouco pode fazer pelos cidadãos, pois nem mesmo a eleição de Barack Obama nos Estados Unidos conseguiu reduzir significativamente os privilégios dos especuladores, apesar da ajuda bilionária do Estado para contornar a crise do sistema.

A insegurança no trabalho e a estagnação dos salários, as mudanças tecnológicas contínuas e o enfraquecimento das instituições públicas ante as forças do mercado, entre outros fatores, despejam sobre o conjunto da população uma sobrecarga emocional que também têm levado a um aumento significativo das patologias mentais. Na França, a depressão aumentou em 60\% entre 1980 e 1990 (PERES, 2003). Somente no ano de 2001 foram consumidas 33,7 bilhões de doses de tranquilizantes no mundo (CEBRID, 2003) e no Brasil os casos de suicídio aumentaram quase 30\% entre 1980 e 2006 (LOVISI et al., 2009). Nos países mais afetados pela crise, redes sociais de proteção como a família converteram-se em redutos de intensa insegurança. Em muitos lares, a maioria de seus membros encontra-se em condições de endividamento severo, desemprego e trabalho precário, não podendo servir como base de apoio para as outras partes (SANTOS, 2011). 
A partir de condições econômicas anômicas geradas pela Depressão de 1929 surgiram os regimes totalitários na Europa, mais especificamente o fascismo e o nazismo. $\mathrm{Na}$ atualidade, esse perigo persiste e existem fortes evidências de que uma democracia meramente formal, incapaz ou ineficiente em proteger seus cidadãos dos efeitos negativos das crises econômicas, pode servir de combustível para a política reacionária. Neste sentido, Santos alerta para a disseminação do fascismo social, que difere do fascismo dos anos 1930-1940, mantendo a mesma essência opressiva. Segundo este autor:

O meu propósito é, pois, o de mostrar que os perigos que a democracia enfrenta não estão no regresso do fascismo na forma histórica que conhecemos. Estão antes na emergência de relações sociais que geram desigualdades tão acentuadas entre os cidadãos ou os grupos sociais que as salvaguardas da democracia pouco valem para defender os cidadãos ou grupos oprimidos no seio dessas relações. Esses cidadãos ou grupos vivem sob microditaduras no seu quotidiano e nas relações sociais, apesar de no plano político serem cidadãos livres e iguais no pleno exercício formal (mas não real) dos seus direitos democráticos [...] não se trata de um regime político mas antes de um regime social e civilizacional. Em vez de sacrificar a democracia às exigências do capitalismo, promove a democracia até o ponto de não ser necessário, nem sequer conveniente, sacrificar a democracia para promover o capitalismo (SANTOS, 2011, p. 118).

O fascismo social não necessita de um líder carismático de massas, tampouco de uma polícia secreta ou supressão de direitos políticos. Esse poder é exercido cotidianamente através de formas variadas de assédio moral em empresas públicas ou privadas, através de companhias de cartões de crédito ou outros tipos fáceis de empréstimos que são oferecidos a pessoas com necessidades urgentes e salários comprimidos. O fascismo social se nutre da atual precariedade da existência civil em tempos de economia financeirizada, na era do capital volátil e densamente concentrado nas mãos de poucos. $\mathrm{O}$ medo e a ansiedade generalizados são os principais motivadores do fascismo social.

Uma vez que os indivíduos se identificam cada vez mais como consumidores do que como cidadãos, o espaço público também vai perdendo a sua função. No mundo do trabalho, a individuação erode os vínculos com os sindicatos e as profissões perdem seu caráter de categoria. A política trona-se serva da economia, com sua lógica individualista e calculista, perpassando todas as relações sociais, incluindo as mais íntimas. Como bem salienta Alain Tourraine (2011, p. 84), "a globalização econômica não engendrou uma globalização política [...] a luta pelo aprofundamento da democracia é necessariamente uma luta anticapitalista". Em síntese, a mera existência de "eleições livres" não garante a melhoria das condições de vida e trabalho das populações, uma vez que a democracia pode facilmente 
transformar-se em uma farsa midiática de forte apelo emocional e publicitário, mas sem tocar o âmago dos problemas.

É tentador para qualquer analista exercer o dom da "futorologia", pois em virtude da rapidez das mudanças que caracterizam nossa época, tais empreitadas tornamse cada vez mais arriscadas. O declínio da atividade econômica mundial é um fato inconteste. Segundo dados do Fundo Monetário Internacional (FMI), a partir da recente crise, a economia presenciou uma desaceleração do patamar de 5\% ao ano, entre 2006 e 2007, para 2,2\% em 2009. O comércio internacional, por sua vez, caiu de 7,2\% em 2007 para 2,1\% em 2009 (MAZZUCCHELLI, 2008).

Neste sentido, vários países terão que lidar com esse declínio da atividade econômica, o que implicará em um aumento da precariedade no trabalho, do desemprego e da fome nos países mais pobres ${ }^{1}$. Na Europa, os sistemas de proteção social e redução das desigualdades estão sendo desmantelados em virtude da aplicação das medidas de austeridade para conter o endividamento do Estado que, por sua vez, foi gerado pelas políticas de auxílio ao sistema financeiro. $\mathrm{O}$ Fundo Monetário Internacional (FMI) aplica agora aos países europeus o receituário que a América Latina experimentou nas décadas de 1980 e 1990. Em poucas palavras, o Consenso de Washington desembarcou no continente europeu.

\section{Considerações finais}

As desigualdades sociais deixaram de ser uma característica dos países do antigo Terceiro Mundo e hoje assumem caráter global. Por outro lado, nunca é tarde para lembrar que alguns grupos sociais antes marginalizados tiveram a oportunidade de ingressar no mundo do consumo. As mulheres possuem mais acesso ao mercado de trabalho que nas décadas anteriores e a informação tornou-se mais disponível a amplas parcelas da população mundial.

Para buscar compreender o papel da democracia no atual contexto é importante refletir sobre um recente evento ocorrido em uma ilha gelada situada no extremo norte da Europa, a Islândia.

Em 2009, os principais bancos privados islandeses foram à falência, como consequência da especulação financeira. Como o Estado islandês não assumiu a dívida, países credores como Inglaterra e Holanda pagaram 3.900 milhões de

\footnotetext{
${ }^{1}$ Sobre a atual crise de alimentos, Zizek (2011, p. 75) comenta: "A crise financeira tornou impossível ignorar a irracionalidade gritante do capitalismo global. Comparem-se os 700 bilhões de dólares gastos somente pelos Estados Unidos para estabilizar o sistema bancário com o fato de que até agora, dos 22 bilhões de dólares prometidos pelos países mais ricos para ajudar o desenvolvimento da agricultura nos países mais pobres diante da crise de alimentos, só 2,2 bilhões foram liberados".
} 
euros e pediram reembolso. O parlamento cogitou em pagar a conta, mas o presidente da Islândia vetou a lei. Os cidadãos daquela ilha, inconformados com o sequestro da democracia e a pilhagem do país por parte dos especuladores, então decidiram organizar um referendo para resolver a questão. O resultado foi que 93\% dos islandeses votaram contra o pagamento da dívida, que seria apenas mais uma medida de "socialização das perdas" em favor dos banqueiros.

Posteriormente, o parlamento islandês conseguiu negociar a dívida, reduzindo os juros de 5,5\% para 3\%, passando o prazo de pagamento de 8 para 30 anos. Inconformadas, as agências de rating usaram as mesmas táticas de terror que aplicam a outros países, ameaçando baixar a nota da Islândia com o objetivo de debilitar ainda mais a sua economia e favorecer o mercado financeiro. Mas essa estratégia de intimidação não surtiu efeito. No momento, o caso está nos tribunais, mas o bolso dos islandeses ficou mais aliviado. Essa não seria uma lição a ser aprendida pelas modernas democracias?

A crise de 2008 também propiciou o surgimento de uma série de manifestações e rebeliões em todo o mundo, como as revoltas da "Primavera Árabe" nos países do Oriente Médio e nos subúrbios de Londres, os Indignados na Espanha, a ocupação da praça Syntagma na Grécia, o movimento Ocupe Wall Street nos Estados Unidos, entre outros (HARVEY et al., 2012). Tais iniciativas não possuem uma ideologia unificada, tampouco uma "carta de intenções" como ocorria entre os militantes comunistas de outrora. Mas todos eles se insurgem contra um inimigo comum: a força do grande capital sob o controle de banqueiros que conseguem lucrar bilhões de dólares ao mesmo tempo em que milhares de indivíduos ao redor do mundo são condenados a uma existência material, social e psíquica cada vez mais precária.

Os recentes movimentos de contestação da atual ordem econômica e social ocorreram de forma espontânea e cosmopolita, utilizando-se, sobretudo, das novas mídias sociais. Embora o discurso de tais grupos seja algumas vezes "nebuloso" com relação a propostas concretas de mudança, com certeza eles representam o início de uma mudança social que não pode ser desprezada e certamente terá significativo impacto sobre as gerações vindouras.

\section{Referências}

BAUMAN, Zygmunt. Capitalismo parasitário: e outros temas contemporâneos. Rio de Janeiro: Jorge Zahar, 2010.

BOURDIEU, Pierre. Contrafogos: táticas para enfrentar a invasão neoliberal. Rio de Janeiro: Jorge Zahar, 1998. 
BRESSER-PEREIRA, Luiz Carlos. A crise financeira global e depois: um novo capitalismo? Novos Estudos, CEBRAP, n. 86, p. 51-72, mar./2010.

CARDOSO, Fernando Henrique. Xadrez internacional e social-democracia. São Paulo: Paz e Terra, 2010.

CASTELLS, Manuel. Fim de milênio. 3 ed. São Paulo: Terra e Paz, 1999. (A era da informação: economia, sociedade e cultura; v. 3).

CEBRID. Centro Brasileiro de Informações sobre Drogas Psicotrópicas. Boletim no 47. Secretaria Nacional Antidrogas: jan./fev./mar., 2003.

CREDIT SUISSE. Global wealth is expected to increase $61 \%$ by 2015 ; middle segment of wealth pyramid holds one-sixth of global wealth, to become emerging consumers and drive economic growth. Press release. Disponível em: <http://www.credit-suisse.com/news/en/media_release.jsp?ns $=41610>$. Acesso em: 15 mar. 2011.

FRIGOTTO, Gaudêncio. Educação, crise do trabalho assalariado e do desenvolvimento: teorias em conflito. In: FRIGOTTO, Gaudêncio; KUENZER, Acácia; GENTILI, Pablo (Orgs.). Educação e crise do trabalho: perspectivas de final de século. 10 ed. Petrópolis/RJ: Vozes, 2011.

GENTILI, Pablo. Educar para o desemprego: a desintegração da promessa integradora. In: FRIGOTTO, Gaudêncio; KUENZER, Acácia; GENTILI, Pablo (Orgs.). Educação e crise do trabalho: perspectivas de final de século. 10. ed. Petrópolis/RJ: Vozes, 2011.

HARVEY, David. Condição pós-moderna. 9. ed. São Paulo: Loyola, 2000. et al. Occupy. São Paulo: Boitempo: Carta Maior, 2012.

HELD, David; McGREW, Anthony. Prós e contras da globalização. Rio de Janeiro: Jorge Zahar, 2001.

IANNI, Octavio. Teorias da globalização. 8. ed. Rio de Janeiro: Civilização Brasileira, 2000.

LOVISI, Giovanni Marcos et al. Análise epidemiológica do suicídio no Brasil entre 1980 e 2006. Revista Brasileira de Psiquiatria, 31 (Supl. II), p. 86-93, 2009. 
MAZZUCCHELLI, Frederico. A crise em perspectiva: 1929 e 2008. Novos Estudos, CEBRAP, n. 82, p. 57-66, nov./2008.

MOTA, Leonardo de Araújo e. Aflição e ajuda mútua em tempos de globalização. Estudos de Sociologia, Recife, v. 10, p. 155-184, 2004.

PERES, Urania Tourinho. Depressão e melancolia. Rio de Janeiro: Jorge Zahar, 2003.

PNUD. Relatório do Desenvolvimento Humano: globalização com uma face humana. Lisboa: Programa das Nações Unidas para o Desenvolvimento. 1998. Disponível em: <http://www.pnud.org.br/rdh/rdh99/index.php >. Acesso em: mar. 2011.

SANTOS, Boaventura de Sousa. Portugal: ensaio contra a autoflagelação. São Paulo: Cortez, 2011.

SENNETT, Richard. A cultura do novo capitalismo. Rio de Janeiro: Record, 2006.

TOURAINE, Alain. Após a crise: a decomposição da vida social e o surgimento de atores não sociais. Petrópolis/RJ: Vozes, 2011.

ZIZEK, Slavoj. Primeiro como tragédia, depois como farsa. São Paulo: Boitempo, 2011.

Endereço para correspondência:

Leonardo de Araújo e Mota-leonardomota@uepb.edu.br R. Baraúnas, 351, Centro de Integração Acadêmica 58429-500 Campina Grande/PB, Brasil 